\title{
The Relation Between Using Inappropriate Medications and Quality of Life Among the Elderly Living in Kerman
}

\section{VIDA Kardanmoghadam}

Research Center for Health Services Administration, Institute of Future Studies in Health, Kerman University of Medical Sciences, Kerman, Iran

\section{Leila Vali}

Research Center for Health Services Administration, Institute of Future Studies in Health, Kerman University of Medical Sciences, Kerman, Iran

\section{Narges Khanjani}

Neurology Research Center, Kerman University of Medical Sciences, Kerman, Iran.

\section{Mohammadreza Amiresmaili ( $\sim$ mohammadreza.amiresmaili@gmail.com )}

Research Center for Health Services Administration, Institute of Future Studies in Health, Kerman University of Medical Sciences, Kerman, Iran.

\section{Kourosh Rajabkhah}

Health Technology Assessment Group, Deputy of Treatment, Ministry of Health and Medical Education, Tehran, Iran

\section{Research Article}

Keywords: Beers criteria, elders, inappropriate medication, life quality

Posted Date: December 28th, 2020

DOl: https://doi.org/10.21203/rs.3.rs-122198/v1

License: (c) (i) This work is licensed under a Creative Commons Attribution 4.0 International License. Read Full License 
The relation between using inappropriate medications and quality of life among the elderly living in Kerman

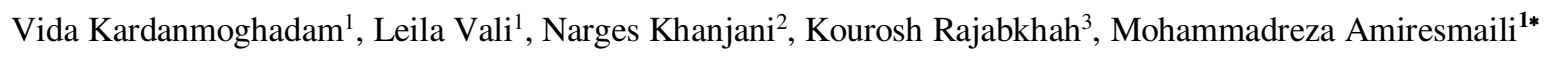

\begin{abstract}
Background: Disability induced by severe diseases reduces life quality among elders, and leads to increased use of medications and increase in drug misuse. This study was done to determine the relation between the number of inappropriate medications used and life quality of elderly people living in Kerman during 2014.

Methods: This cross-sectional study was conducted on 107 elderly people in Kerman, Iran. The participants were selected by simple random sampling. The elderly health assessment questionnaire and Beers Criteria were used for data collection. Data were analyzed using SPSS (version 16) and running $\chi^{2}$ test, Fischer's Exact test, and logistic regression. The model fitness was evaluated by the Hosmer and Lemeshow Test.

Results: The risk of low life quality in elders using 3 to 4 inappropriate medications was 9.98 times more than elders using no unauthorized medication. The most frequent inappropriate medications were Aspirin and Alprazolam. A significant relation was observed between low life quality and number of inappropriate medications used by elders; that is, taking a higher number of inappropriate medications was associated with lower life quality.
\end{abstract}

Conclusions: Many elderly people use inappropriate medications, which can have a serious adverse impact on their quality of life

Key words: Beers criteria, elders, inappropriate medication, life quality

\section{Background}

The dramatic increase in average life expectancy during the $20^{\text {th }}$ century is a big achievement (1). Global population ageing is one of the most notable social transformations of the twenty-first century. Aging is a biological process that all living creatures, including human beings experience. The advances in medical knowledge and technologies in today's world have increased life expectancy and the number of elderly people.

\footnotetext{
${ }^{1}$ Research Center for Health Services Administration, Institute of Future Studies in Health, Kerman University of Medical Sciences, Kerman, Iran.

${ }^{2}$ Neurology Research Center, Kerman University of Medical Sciences, Kerman, Iran.

${ }^{3}$ Health Technology Assessment Group, Deputy of Treatment, Ministry of Health and Medical Education, Tehran, Iran

${ }^{*}$ Correspondence: Research Center for Health Services Administration, Institute of Future Studies in Health, Kerman University of Medical Sciences, Kerman, Iran. Tel: 98-935-480-4513. E-mail: Mohammadreza.amiresmaili@gmail.com
} 
Currently, the rapid increase of the aged population has highlighted issues related to this age group. Generally, with increase in age, the likelihood of illnesses and incapability increases. These negative effects increase the elderlies need for help, affect their independence and reduce their Quality of Life (QoL) (2). Today, for the first time in history, most people can expect to live into their sixties and beyond. By 2050, the world's population aged 60 years and older is expected to reach 2 billion. Now, 125 million people are aged 80 years or older. By 2050, there will be almost this many (120 million) living in China alone, and 434 million people in this age group worldwide. By 2050, $80 \%$ of all older people will live in low- and middle-income countries (1). Currently, the elderly population of Iran is $8.2 \%$ of the total population $(3,4)$.

According to international estimates, in the coming years the elderly population of Iran will have a faster growth than the rest of the world and even the world average; and by 2045, Iran will overtake the average global population growth rate for the elderly and five years later will also surpass that of Asia (3). By the middle of the century many countries for e.g. Chile, China, the Islamic Republic of Iran and the Russian Federation will have a similar proportion of older people to Japan , in which $30 \%$ of the population are already over 60 years old (1).

One of the measurable indicators that can be used to determine and improve the needs and health conditions of the elders is QoL. Studying healthrelated QoL has become one of the important areas of geriatric research and is regarded as one of the key indicators for assessing the efficacy of therapeutic and care interventions (5). QoL is a multi-dimensional concept that reflects the level of satisfaction and the current functioning of the individual(6). The World Health Organization (WHO) defines QoL as "an individual's perception of their position in life in the context of the culture and value systems in which they live and in relation to their goals, expectations, standards and concerns". Assessment of Health Related Quality of Life (HRQoL) has become one of the important research outcomes and is one of the important indicators of intervention efficacy (7).

Elderly people suffer from more illness and disability and consume more drugs in comparison with young people (8). The increase in drug consumption among the elderly, considering their decreased ability to metabolize and eliminate the drugs, increases the risk of adverse health effects, especially if the dose is not adjusted properly. Excessive consumption of some medications, especially among the elderly, increases the incidence of side effects, which in some cases are very serious and can threaten the patient's life. Some of these side effects are unwanted and unavoidable. Research has also shown that simultaneous use of multiple medications may cause severe and sometimes toxic effects in the elderly. This is because of the physiological changes in the elderly and disruptions in compensatory mechanisms that might cause changes in response to standard drug concentrations. The use of inappropriate drugs is a common problem in the elderly of all 
communities. Consumption of these medications is often not monitored and requires physicians' and pharmacists' attention. Any minor negligence in prescribing medications can lead to additional problems, especially in the vulnerable seniors (9).

The results of Steven's research in 2016 showed that in general, $37.2 \%$ of the elderly in 6 provinces (British Columbia, Alberta, Saskatchewan, Manitoba, Ontario and Prince Edward Island) consumed at least one inappropriate drug. The highest prevalence of prescribing inappropriate drugs was $40.7 \%$ in the Canadian province of Alberta, whereas the lowest rate was 29.2\% in Prince Edward Island (10).

Inappropriate drugs are drugs with higher risks than benefits, while safe alternatives are available. Taking inappropriate drugs can lead to adverse drug reactions (11).

In several studies, the prevalence of using inappropriate medications among elders was estimated between $12 \%$ to $40 \%$ (11-13).

In the elderly, two thirds of unwanted side effects are caused by consumption of drugs such as corticosteroids, non-steroidal anti-inflammatory drugs, cardiovascular drugs, and psychotropic drugs (14).

Vali estimated that $20.75 \%$ of the elderly in Tehran consumed inappropriate drugs; and the most commonly used drugs were benzodiazepines (49.98\%). Their findings showed that the use of inappropriate drugs among the elderlies of Iran is higher than many other countries and the use of such drugs exposes the elderlies to adverse drug reactions (8).
Apart from the economic and social issues of the aging phenomenon, aging has caused disease patterns to change to chronic diseases such as cardiovascular disease, cancer, high blood pressure, and diabetes (7).

Considering the importance of QoL in this group, there is a need for innovative planning and modifications in the country's policies and programs. This can be achieved through focusing on elders' empowerment and enhancing their health and welfare (5). The aim of this research was to determine the relation between QoL and taking inappropriate medications among elders living in Kerman, Iran.

\section{Material and method:}

The present descriptive- analytical, crosssectional study was conducted on all elders discharged from Kerman University hospitals during the first six months of 2013. The addresses of elders were found using their hospital medical records. Simple random sampling was conducted to select the participants.

Before initiating the study, all participants were informed about the objectives of the study and informed consent was obtained from all the participants. Some participants were living in other cities and had provided their children's address in Kerman at the time of discharge.

The inclusion criteria included residence of the elderly in Kerman and age $\geq 60$ years. In case an elderly did not want to cooperate in the study, he/she was excluded. 
The interviews were done in the participants' house by a trained interviewer. The interviewer recoded participants' demographic information and completed the questionnaire. In addition, information about the medications taken by each participant, the insurance booklet, shells and boxes of medications were recorded.

The consumed inappropriate drugs were recorded on the Beers checklist. These criteria were first published in 1991 by researchers at the University of California, USA, and were the first public benchmark for identifying the use of inappropriate drugs among residents of nursing homes (15). The consumed drugs might have minor or severe side effects for the elderly based on their type and category. The Beers' criteria were re-evaluated and updated in 2003 (Additional file 1: Table S1); and consists of 48 medicines and categories (16).

The validity of the standard questionnaire (the Nottingham Health Profile (NHP)) (Additional file 2: Table S2) used in the current study was confirmed in previous studies (7). The Cronbach's Alpha of the NHP questionnaire was 0.938 (8). The NHP questionnaire includes 38 questions in six dimensions designed to evaluate the perception of health by each individual. In addition, it is used as a standard tool for investigating health problems in the society.

The number of questions in each dimension includes physical mobility (8 questions), pain ( 8 questions), sleep (5 questions), energy (3 questions), emotional reactions (9 questions), and social isolation (5 questions). Response to each question is "yes or no". 1 is considered for a positive answer and 0 for a negative answer. The weight of scores for each question in each dimension is so that the total scores of questions in each dimension is 100; and higher scores show lower health levels. The mean value of QoL aspects was calculated. Scores $\geq 45.22$ indicated undesirable and scores $<45.21$ indicated desirable QoL(10).

$\chi^{2}$ test, Fisher's exact test, and logistic regression were run for determining the relation between QoL and the consumption of inappropriate medications. Model fitness in logistic regression was evaluated by the Hosmer and Lemeshow's test.

The calculated sample size used to assess the QoL of the elderly in this study was at least 101 participants, and was calculated based on the standard deviation of 10.22 (17) and the acceptable error of 2. After completing the Beer's criterion checklists by the participants, data were analyzed using SPSS (version 16).

\section{Results}

The demographic characteristics of participants have been shown in Table 1. 150 elderly people participated, 77 persons were women and 73 were men. The mean age of the participants was $72.8 \pm 8.04$ years (Additional file 3: Table S3). 
Table 1: The Demographic characteristics of elders who participated in this study

\begin{tabular}{|c|c|c|c|}
\hline \multicolumn{2}{|c|}{ Variable } & Frequency & Number (\%) \\
\hline \multirow{2}{*}{ Sex } & Female & 77 & 51.3 \\
\cline { 2 - 4 } & Male & 73 & 48.7 \\
\hline \multirow{3}{*}{ Age } & $60-70$ years & 67 & 38.7 \\
\cline { 2 - 4 } & $71-80$ years & 58 & 16.7 \\
\cline { 2 - 4 } & $>80$ years & 25 & 60.5 \\
\hline \multirow{2}{*}{ Marital status } & Married & 89 & 39.5 \\
\hline \multirow{3}{*}{ Education } & Widowed & 58 & 66 \\
\cline { 2 - 4 } & Illiterate & 39 & 26 \\
\cline { 2 - 4 } & Elementary school education & 12 & 32.7 \\
\cline { 2 - 4 } & Uchool Diploma or higher & 49 & 25.3 \\
\cline { 2 - 4 } & Unemployed & 38 & 22.7 \\
\cline { 2 - 4 } & Retired & 34 & 19.3 \\
\cline { 2 - 4 } & Self-employed & 29 & \\
\hline
\end{tabular}

The findings showed that $71.3 \%$ of the elderly consumed inappropriate drugs and $46.7 \%$ used more than one inappropriate drug. Considering side effects, $95.3 \%$ of the consumed drugs could exert severe complications in the elders.

The frequency of the components of total QoL in the elderly according to participants' demographic characteristics is showed in Table2.

According to Table 2, physical mobility in the elderly had a significant relation with gender, age, and marital status. Desirable physical mobility was more in men than women $(\mathrm{P}=0.03)$. Moreover, it had the highest frequency among elderly who were between $60-70$ years old than others $(\mathrm{P}=0.001)$. It was also more frequent among married ones $(\mathrm{P}<0.001)$.

Moreover, there was a significant relation between the relative frequency of pain and age $(\mathrm{P}$ $=0.006)$ and marital status $(\mathrm{P}=0.04)$. With increase in age, the frequency of unfavorable pain increased $(\mathrm{p}<0.001)$. Furthermore, the severity of pain in older people whose spouses had died was higher than the elderly who lived with their spouses $(\mathrm{p}=0.04)$.

As seen in table 2, there was a significant relation between the elder's age and their quality of sleep; and a higher percentage of elderly people older than 80 years old had unfavorable sleep quality $(\mathrm{P}=0.04)$. Also, the elderly whose spouses had died had worse sleep quality compared to elderly people living with their spouses $(\mathrm{P}=0.05)$. A higher percentage of unemployed or selfemployed elderly people had unfavorable quality of sleep $(\mathrm{P}=0.03)$. Other variables were not significantly related to quality of sleep.

Females had a more unfavorable situation than the males in the energy component and this difference was significant $(\mathrm{p}=0.03)$. Energy was significantly related to age and older people had less energy $(p=0.004)$. The elderly whose spouse had died, had significantly more unfavorable conditions in the energy component compared to 
the elderly who lived with their spouses ( $p$ $<0.001)$.

As table 2 shows, social isolation was more remarkable in women $(\mathrm{P}=0.02)$, those aged $>80$ years $(\mathrm{P}<0.001)$, the elderly whose spouse had died $(\mathrm{P}<0.001)$, and the elderly who were housekeepers $(\mathrm{P}=0.02)$. There was a significant relation between emotional reactions and educational level $(\mathrm{P}=0.05)$ and job $(\mathrm{P}=0.03)$. That is, the prevalence of undesirable emotional reactions was significantly higher among illiterate people than people with elementary education. More unemployed elderly had unfavorable emotional reactions.

In general, a significant relation was found between $\mathrm{QoL}$ and gender $(\mathrm{P}=0.03)$, age $(\mathrm{P}=$ $0.001)$, and marital status $(\mathrm{P}<0.001)$. In other words, QoL was lower in females and those who were older. The prevalence of unfavorable QoL was significantly higher among the elderly whose spouses had died than the elderly living with their spouses.

The frequency of the elderlies' life quality in terms of the number, and the severity and possible complications of inappropriate drugs is reported in Table 3.

According to Table 3, a significant relation was observed between QoL and the number of inappropriately consumed drugs among the elderly. The elderly who consumed 3 to 4 inappropriate drugs had more unfavorable QoL than those who took none or one inappropriate medication.

Table 3: Comparison of the frequency of total QoL in the elderly according to the number and severity of possible complications of inappropriate drugs

\begin{tabular}{|c|c|c|c|c|}
\hline \multirow{2}{*}{\multicolumn{2}{|c|}{ Inappropriate Drug Indicators }} & \multicolumn{2}{|c|}{ QoL Indicators } & \multirow{2}{*}{ P-Value } \\
\hline & & $\begin{array}{l}\text { Undesirable } \\
(\%)\end{array}$ & $\begin{array}{l}\text { Desirable } \\
(\%)\end{array}$ & \\
\hline \multirow{4}{*}{ The number of improper used drugs } & 0 & $(37.2) 16$ & $(62.8) 27$ & \multirow{4}{*}{0.01} \\
\hline & 1 & (48) 24 & (52) 26 & \\
\hline & 2 & $(52.4) 22$ & (47.6) 20 & \\
\hline & $3-4$ & (86.7) 13 & $(13.3) 2$ & \\
\hline \multirow{2}{*}{$\begin{array}{c}\text { The severity and possible side effects of inappropriate } \\
\text { used drugs according to the Beers' criteria }\end{array}$} & Low & (20) 1 & (80) 4 & \multirow{2}{*}{$0.11 *$} \\
\hline & High & (56.9) 58 & $(43.1) 44$ & \\
\hline
\end{tabular}

*Fisher's Exact

According to table 4 and the results of one-way analysis of variance, the mean score of undesirable quality of life in all dimensions except energy dimension, was significantly different in various groups of inappropriate drugs use and was worse in groups that used more drugs $(\mathrm{p}<0.05)$. Undesirable physical mobility was observed in the elderly who took 3-4 drugs, which was higher than the elderlies who did not use any inappropriate medication, and this difference was statistically significant $(\mathrm{P}=0.02)$. In addition, significant difference was observed in the 
frequency of pain, sleep, social isolation, and emotional reactions of the elderly according to the number of possible complications of inappropriate drug use $(\mathrm{P}<0.05)$.

Table 4: The mean score of life quality and its components among the elderly in terms of the number of inappropriate drug use

\begin{tabular}{|c|c|c|c|c|}
\hline Variable & $\begin{array}{c}\text { Number of inappropriate } \\
\text { drugs }\end{array}$ & Mean & $\begin{array}{l}\text { Standard } \\
\text { deviation }\end{array}$ & P-value \\
\hline \multirow{4}{*}{ Physical mobility } & 0 & 45.48 & 28.50 & \multirow{4}{*}{0.02} \\
\hline & 1 & 46.80 & 26.48 & \\
\hline & 2 & 47.67 & 22.95 & \\
\hline & $3-4$ & 68.86 & 36.85 & \\
\hline \multirow{4}{*}{ Pain } & 0 & 45.54 & 28.61 & \multirow{4}{*}{0.04} \\
\hline & 1 & 44.32 & 30.18 & \\
\hline & 2 & 40.11 & 33.82 & \\
\hline & $3-4$ & 64.54 & 25.77 & \\
\hline \multirow{4}{*}{ Sleep } & 0 & 35.31 & 29.55 & \multirow{4}{*}{0.05} \\
\hline & 1 & 44.03 & 27.27 & \\
\hline & 2 & 48.41 & 27.91 & \\
\hline & $3-4$ & 57.80 & 35.21 & \\
\hline \multirow{4}{*}{ Energy } & 0 & 53.73 & 39.51 & \multirow{4}{*}{0.09} \\
\hline & 1 & 53.60 & 36.25 & \\
\hline & 2 & 54.22 & 36.77 & \\
\hline & $3-4$ & 79.89 & 31.59 & \\
\hline \multirow{4}{*}{ Social isolation } & 0 & 29.79 & 28.61 & \multirow{4}{*}{0.02} \\
\hline & 1 & 39.32 & 30.84 & \\
\hline & 2 & 41.25 & 34.40 & \\
\hline & $3-4$ & 59.02 & 32.50 & \\
\hline \multirow{4}{*}{ Emotional reactions } & 0 & 43.89 & 43.89 & \multirow{4}{*}{0.01} \\
\hline & 1 & 47.92 & 47.92 & \\
\hline & 2 & 51.66 & 51.66 & \\
\hline & $3-4$ & 70.63 & 70.63 & \\
\hline \multirow{4}{*}{ Life quality } & 0 & 42.29 & 23.50 & \multirow{4}{*}{0.005} \\
\hline & 1 & 46 & 21.76 & \\
\hline & 2 & 47.22 & 22.98 & \\
\hline & $3-4$ & 66.79 & 23.32 & \\
\hline
\end{tabular}


The results of logistic regression in table 5 show that participants who used 3 to 4 inappropriate medications had the chance of experiencing an undesirable life quality 9.98 (95\% CI: 1.8952.57) times more than those who used no inappropriate medications.

Furthermore, the odds of having low life quality was 1.89 (95\% CI: 0.92-3.91) and 8.2 (95\% CI: 2.4-26.7) times higher in elderly people aged between 71-80 years and those aged over 80 years in comparison with the elderly aged 60-70 years, respectively. The results showed that the odds of having undesirable life quality was less $(0.35$, 95\% CI: 0.15-0.864) among people who were retired compared to the unemployed. In addition, the odds of unfavorable life quality was less (0.477, 95\% CI: 0.223-1.02) in the elderly with higher education than those who were illiterate.

Table 5: Adjusted odds ratio for the prdictors of Quality of Life among the elderly

\begin{tabular}{|c|c|c|c|}
\hline \multicolumn{2}{|c|}{ Variables } & \multirow{2}{*}{$\begin{array}{c}\text { OR (95\% Confidence Interval) } \\
1\end{array}$} & \multirow{2}{*}{$\frac{\text { P-Value }}{-}$} \\
\hline \multirow{4}{*}{$\begin{array}{c}\text { Inappropriate } \\
\text { used } \\
\text { drugs(count) }^{*}\end{array}$} & 0 & & \\
\hline & 1 & $1.39(0.58-3.34)$ & 0.46 \\
\hline & 2 & $1.83(0.74-4.45)$ & 0.20 \\
\hline & $3-4$ & $9.98(1.89-52.57)$ & 0.007 \\
\hline \multirow{2}{*}{ Sex } & Female & 1 & - \\
\hline & Male & $0.796(0.236-1.344)$ & 0.196 \\
\hline \multirow{2}{*}{ Insurance } & No & 1 & - \\
\hline & Yes & $0.287(0.047-1.756)$ & 0.176 \\
\hline \multirow{3}{*}{ Education } & illiterate & 1 & - \\
\hline & $\begin{array}{l}\text { Elementary school } \\
\text { education }\end{array}$ & $0.509(0.135-1.92)$ & 0.319 \\
\hline & $\begin{array}{c}\text { High School Diploma or } \\
\text { higher }\end{array}$ & $0.477(0.223-1.02)$ & 0.056 \\
\hline \multirow{4}{*}{ Job } & Unemployed & 1 & - \\
\hline & Retired & $0.35(0.15-0.864)$ & 0.02 \\
\hline & self-employed & $0.69(0.281-1.69)$ & 0.417 \\
\hline & housewife & $0.961(0.38-2.48)$ & 0.961 \\
\hline \multirow{3}{*}{ Age } & $60-70$ years & 1 & - \\
\hline & $70-80$ years & $1.89(0.92-3.91)$ & 0.083 \\
\hline & 80 years $<$ & $8.2(2.4-26.7)$ & 0.001 \\
\hline \multirow{2}{*}{ Marital status } & Widowed & 1 & - \\
\hline & Married & $1.7(0.793-4.097)$ & 0.159 \\
\hline
\end{tabular}




\section{Discussion}

In the present study, the mean score of QoL in the elderly was $47.36 \pm 23.53$ from 100 , and the QoL score of the elderly was generally favorable in Kerman. Regression analysis of the results indicated that QoL of the elderly had a significant relation with their age, gender, and marital status. In other words, with increase of age, the elderly had more unfavorable QoL. In similar studies about the effect of age on QoL, significant and inverse relations were found between age and QoL (18). Results of the current study are in line results of other studies that reported total quality of life is lower among the older seniors than the other age groups. A study in Australia showed that the elderly under 70 years of age had better health and QoL than those who were more than 70 years old (19). Obviously, the incidence of physical inability and moving limitations are more pronounced in older people, and this affects their QoL.

Moreover, a greater percentage of female elderly had undesirable QoL than males. Elderly women experience more functional disability compared to older men. Health statistics show more high physical inability and more use of health services among women. The reason for better physical activity status among elderly men compared to the elderly women seems to be the fact that women are more likely to suffer from articular and bone diseases than men, and therefore have more difficulty in doing their daily activities and exercises (20). In examining the relation between gender and life quality of the elderly, the results of similar studies indicate higher QoL scores for elderly men in all aspects of life quality $(19,21$ 25). Some studies have shown a significant statistical difference for life quality, only in physical dimensions and social function which was more among men than women $(24,26,27)$. However, in our study, in all aspects, the life quality scores of the elderly men were higher than those of the elderly women, which can be due to cultural and social factors of the community.

According to the results of this study, undesirable life quality was more prevalent among elderly people whose spouse had died and was significantly higher than the elderly who lived with their spouses. One of the social factors affecting QoL is partner support and the social networks people interact with them. The absence of this factor in the elderly whose spouse has passed away or those who live alone can affect their health and quality of life. Therefore, social and support networks should be created for the elderly people. They should also be empowered adequately to face the complications caused by lack of these supportive networks. Anderson (2006), and Owens (1990) showed that spouses have a decisive role in improving the satisfaction in elderly life $(28,29)$. Furthermore, other studies have emphasized on the positive role of marriage in the quality of life of individuals $(18,19)$. However, this relation was not confirmed in Lehman's study in 1995 (30).

The findings of this research revealed that familial relationships and social support had a significant effect on QoL of the elderly. 
Therefore, particular attention should be paid to improve relationships in families with elderly members. Generally, with increase of age, the likelihood of developing diseases and incapability increases in the final years of life. This issue requires more attention to the supportive factors and other basic variables to empower the elderlies, make their lives more dynamic, and improve their QoL. The study of Tajvar showed that the socio-cultural conditions in Iran have made mental health status better than physical health, because in Iran the elderly receive special respect and have a highly respected position in their families (31). The cultural and religious background in Iran has not only prevented people from leaving the elderly, but has also encouraged the younger individuals to take care of them, while in the advanced societies this situation is less common. However, changes have occurred over time, such as the size of families, migration, and various problems leading the elderly to be transferred to nursing homes (32). Carrillo et al., believed that the variety of social support networks and their effects on health is related to the culture. For example, in Mexico, family relationships are the most important type of social network (33). Moreover, a longitudinal study in western societies indicated that people who are members of the social support systems such as family, friends, and peers are healthier, have a longer life, and are more satisfied with their lives (34). In this regard, we can argue that social isolation can lower the function of the body's immune system and increase the activity of the endocrine and cardiovascular systems (35). A study from Finland reported that more than one-third of the elderly suffered from loneliness (36).

In the relation between the elderlies' level of education and their quality of life, significant differences were observed; and the elderly with higher educations had higher average scores than the elderly with lower education levels. This confirms the findings that think education is an effective factor in creating a dynamic elderly life $(19,21-24,37)$.

In this study, uneducated and unemployed elderly people did not have a good quality of life, although the difference with others was not statistically significant. These results are not in line with other studies, which did not show a lower quality of life among uneducated and unemployed elderly people. The difference between the results of the current study and these studies is probably due to the different measurement tools and the community under study $(37,38)$.

In the current study, a significant relation was found between undesirable life quality and the number of inappropriate medications taken by elders, so that elders who used 3 to 4 inappropriate medications had a much more undesirable life quality than elders who used no or 1 inappropriate medication.

A study on the demographic factors of the elderly discharged from the hospitals of Tehran showed that gender and income were associated with consumption of inappropriate drugs among the elderly. The findings indicated that the elderly 
women $(21.5 \%)$ more than men $(11.8 \%)$ and the elderly without income (26.4\%) more than the individuals with income (13.2\%) used inappropriate drugs. The elderly who took more drugs, consumed more inappropriate medicines (28.6\% vs. $12.2 \%)$. However, factors such as age, gender, marital status, occupation, and etc., did not have any relation with inappropriate use of drugs $(7,37)$.

In another study, drug consumption was reported higher among the low-educated or illiterate older people than the educated ones $(48.1 \%$ vs. $1.8 \%)$, because the former group lacked information on the consequences of taking medications, especially the inappropriate drugs. On the other hand, the elderly with higher education levels paid more attention to their health status, which resulted in less use of drugs, especially the inappropriate medications (7). The findings of this study were consistent with the present study. Excessive consumption of some medications, especially among the elderly increases the incidence of side effects. These side effects are sometimes very serious and can threaten the patient's life. Some of these side effects are unwanted and unavoidable.

In a study conducted by Laroche, it was found that women used inappropriate medications more than men; in addition, he found that old elderly people with low education took more inappropriate medications (39). In another research on the relevant factors associated with prescription of inappropriate medications in elders, it was found that patients with myocardial infarction or heart failure used inappropriate medications more than others. Men, individuals with health insurance, and the elderly over eighty-five years used less inappropriate medications (40).

In a study conducted on the elderly admitted to Slovakia hospitals, the use of various medications, depression, lack of mobility, and heart failure were recognized as factors associated with increased prescription of inappropriate medications; moreover, it was found that the prescription of inappropriate medications was less in elders over 74 years (11) . In a study performed in Italy, the rate of prescribing inappropriate medications increased by increase in the length of staying in the hospital and the number of prescribed medications. The related factors associated with prescription of inappropriate medications were age $>85$ years, the existence of cognitive impairment, and the number of various medications (41).

In another research, age $>80$ years, the use of various medications, depression, and poor mental health were found to be risk factors for inappropriate medication prescription (42).

The literature has shown that taking multiple medications simultaneously in many cases, causes more severe and sometimes toxic effects in the elderly. This is due to the physiological changes in the body, which change the quality of drugs, cause disorders in compensatory mechanisms of the body, and change the tissue response to the standard drug concentration. 
Different rates have been reported for inappropriate use of drugs among the elderly population in different countries which may be due to different drug policies, different health care systems, and the health status of the elderly. One of the main objectives of the European Union is to improve measures, rules, and regulations throughout Europe and to coordinate the drug policies with regard to the use of inappropriate medications, such as abandoning ineffective or dangerous drugs, limiting drug administration for the elderly, prescribing safer drugs, and coordinating drug prescription guidelines. These strategies can help improve proper drug prescription among the elderly (43).

The application of such a model can also be beneficial in Iran. One of the major problems with taking medicines in the elderly is its economic dimension. The comprehensive coverage of the elderlies' drug costs brings a huge financial burden to the health care system since the cost of drug treatment for these people is increasing annually. There is, of course, another view that if drug therapy leads to non-hospitalization, reduction of the hospitalization period, better performance of the patient, and prevention of combined illnesses, it can bring down health care costs.

\section{Conclusion}

Considering the increase of the elderly population which is accompanied with various costs, including healthcare, paying attention and planning for this age group seems essential. One of the appropriate solutions to reducing these costs is paying attention to the life quality of the elderly and factors that affect their life quality such as social support. In addition, with regard to the growth of chronic and non-communicable diseases and population aging, training healthcare providers concerning the right concepts of medication therapy among the elderly, should be one of the priorities of medical, pharmaceutical, and nursing universities. Further, informing the consumers should also be considered. For example, pharmacists can inform elders about the medications that they should avoid.

\section{Availability of data and materials}

The full dataset generated and analysed during the current study are not publicly available in order to maintain the privacy of the individuals interviewed during this study. De-identified data can be made available from the corresponding author on reasonable request.

\section{Abbreviations}

QoL: Quality of Life, WHO: World Health Organization, HRQoL: Assessment of Health Related Quality of Life, NHP: Nottingham Health Profile

\section{References}

1. World Health Organization(WHO) WH. Ageing and health. 2018.

2. Saeidimehr S GS, Izadmehr A, Mohammadi MJ. Relationship between the "Quality of Life" and Symptoms of Depression among Older Adults. Iranian Journal of Ageing. 2016;11(1):90-9.

3. Borhaninejad V KL, Haghi M, Chehrehnegar N. Quality of Life and Its Related Factors Among Elderly With Diabetes. Yektaweb_Journals. 2016;11(162-173).

4. Statistical Center of Iran tPsODoSPaC. National population and housing Census 20162018.

5. Mehri Nejad SA, Ramezan Saatchi L, Paydar S. Death anxiety and its relationship with social support and adherence to religion in the elderly. Iranian journal of Ageing. 2017;11(4):494-503. 
6. Zahmatkeshan N, bagherzadeh r, Akaberian S, yazdankhah MR, Mirzaei k, Yazdanpanah S, et al. Assessing Quality Of Life and related factors in Bushehr,s elders - 1387-8. Journal of Fasa University of Medical Sciences. 2012;2(1):53-8.

7. Vali L, Pour Reza A, Rahimi Foroushani A, Ahmadi B, Akbari Kamrani AA. Analysis of inappropriate medication use in older adults discharged from hospitals affiliated with Tehran University of Medical Sciences (TUMS) using the Beers criteria in 2010. Iranian Journal of Ageing. 2011;6(3):56-65.

8. Vali L, Pourreza A, Ahmadi B, Akbari Sari A. Quality assessment tools and Management for medication prescription in elderly. Journal of Hospital. 2013;11(4):25-34.

9. Murray MD. Medication appropriateness index: putting a number on an old problem in older patients. The Annals of pharmacotherapy. 1997;31(5):643-4.

10. Morgan SG, Hunt J, Rioux J, Proulx J, Weymann D, Tannenbaum C. Frequency and cost of potentially inappropriate prescribing for older adults: a cross-sectional study. CMAJ open. 2016;4(2):E346. 11. Imai H, Fick DM, Waller JL, Maclean JR. Physician characteristics associated with prescription of inappropriate medications using Beers criteria. Geriatrics \& Gerontology International. 2007;7(4):380-7.

12. Zhan C, Sangl J, Bierman AS, Miller MR, Friedman B, Wickizer SW, et al. Potentially inappropriate medication use in the communitydwelling elderly: findings from the 1996 Medical Expenditure Panel Survey. Jama. 2001;286(22):28239.

13. Ray WA, Federspiel CF, Schaffner W. A study of antipsychotic drug use in nursing homes: epidemiologic evidence suggesting misuse. American Journal of Public Health. 1980;70(5):485-91.

14. Saboor M. Elderly's Medical Therapy Status. Iranian Journal of Ageing. 2007;2(1):216-22.

15. Beers MH. Explicit criteria for determining potentially inappropriate medication use by the elderly: an update. Archives of internal medicine. 1997;157(14):1531-6.

16. Fick DM, Cooper JW, Wade WE, Waller JL, Maclean JR, Beers MH. Updating the Beers criteria for potentially inappropriate medication use in older adults: results of a US consensus panel of experts. Archives of internal medicine. 2003;163(22):2716-24. 17. Borhaninezhad V, Kazazi L, Haghi M, Chehrehnegar N. Quality of Life and Its Related Factors among Elderly with Diabetes (Per-sian). Iranian Journal of Ageing. 2016;11(4):162-73.

18. Salarvand S, Abedi HA. Causes and motivations of elderly home residency from residents' point of view. Feyz Journal of Kashan University of Medical Sciences. 2008;12.

19. Kirchengast S, Haslinger B. Gender differences in health-related quality of life among healthy aged and old-aged Austrians: cross-sectional analysis. Gender Medicine. 2008;5(3):270-8.

20. Arber S, Cooper H. Gender differences in health in later life: the new paradox? Social science \& medicine. 1999;48(1):61-76.

21. Alipour F, Sajadi H, Foruzan A, Biglarian A, Jalilian A. Elderly quality of life in Tehran's district two. Iranian journal of ageing. 2008;3(3):75-83.

22. Abedi H. A comparative study of life quality of elderly people residing in nursing homes of Isfahan (Dissertation). Isfahan, Iran: Isfahan University of Medical Sciences. 2000:43-56.

23. Mohaqeqi Kamal H, Sajadi H, Zare H, Beiglarian A. Elderly quality of life: a comparison between pensioners of social security organization and national retirement fund (Qom County, 2006). Journal of health administration. 2007;10(27):49-56.

24. Albokorki M, Ramezani M, Arizi F. Quality of life in the elderly of Shahinshahr, 2004. Jundishapur Sci Med J. 2006;5:703-9.

25. Mohammadi E, Allahyari T, Darvishpoor Kakhaki A, Saraei H, Fereshtehnejad SM. Analysis of being active based on older adults' experience: a qualitative study of active aging strategies. Iranian Journal of Ageing. 2017;11(4):504-17.

26. Nia V, Goshtasebi A, Montazeri A, Maftoon F. Health-related quality of life in an elderly population in Iran: A population-based study. Payesh (Health Monitor). 2005;4(2):113-20.

27. Ahangari M, Kamali M, Arjmand Hesabi M. The study of quality of life in the elderly with hypertension who are member of Tehran Senile Culture House Clubs. Iranian Journal of Ageing. 2008;3(1):26-32.

28. Owens NJ, Sherburne NJ, Silliman RA, Fretwell MD. The Senior Care Study: the optimal use of medications in acutely ill older patients. Journal of the American Geriatrics Society. 1990;38(10):1082-7. 29. Andersen M. Is it possible to measure prescribing quality using only prescription data? Basic \& clinical pharmacology \& toxicology. 2006;98(3):314-9.

30. Lehmann H, Syrdal DS, Dautenhahn K, Gelderblom G, Bedaf S, Amirabdollahian F, editors. What should a robot do for you?-Evaluating the needs of the elderly in the UK. Proc 6th Int Conf on Advances in Computer-Human Interactions; 2013.

31. Tajvar M, Arab M, Montazeri A. Determinants of health-related quality of life in elderly in Tehran, Iran. BMC public health. 2008;8(1):323.

32. Teymoori F, Dadkhah A, Shirazikhah M. Social welfare and health (mental, social, physical) 
status of aged people in Iran. Middle East Journal of Age and Ageing. 2006;3(1):39-45.

33. Gallegos-Carrillo K, Mudgal J, SánchezGarcía S, Wagner FA, Gallo JJ, Salmerón J, et al. Social networks and health-related quality of life: a population based study among older adults. Salud publica de Mexico. 2009;51(1):6-13.

34. Sudha S, Suchindran C, Mutran EJ, Rajan SI, Sarma PS. Marital status, family ties, and self-rated health among elders in South India. Journal of CrossCultural Gerontology. 2006;21(3-4):103-20.

35. Seeman TE. Social ties and health: The benefits of social integration. Annals of epidemiology. 1996;6(5):442-51.

36. Routasalo PE, Savikko N, Tilvis RS, Strandberg TE, Pitkälä KH. Social contacts and their relationship to loneliness among aged people-a population-based study. Gerontology. 2006;52(3):181-7.

37. Shaabani J, Rahgoi A, Nourozi K, Rahgozar M, Shaabani M. The relationship between selfefficacy and quality of life among elderly people. Iranian journal of ageing. 2017;11(4):518-27.

38. Sajjadi H, Biglarian A. Quality of life of elderly woman in Kahrizak Charity. Payesh journal. 2007;2:105-8.

39. Laroche ML CJ. Impact of hospitalization in an acute medical geriatric unut on potentially inappropriate medication use. . Drugs Aging. 2006;23:49-59.

40. Gosney M, Tallis R. Prescription of contraindicated and interacting drugs in elderly patients admitted to hospital. The Lancet. 1984;324(8402):564-7.

41. Onder G, Landi F, Cesari M, Gambassi G, Carbonin P, Bernabei R. Inappropriate medication use among hospitalized older adults in Italy: results from the Italian Group of Pharmacoepidemiology in the Elderly. European journal of clinical pharmacology. 2003;59(2):157-62.

42. Pitkala KH, Strandberg TE, Tilvis RS. Inappropriate drug prescribing in home-dwelling, elderly patients: a population-based survey. Archives of Internal Medicine. 2002;162(15):1707-12.

43. Gallagher P, Barry P, O'Mahony D. Inappropriate prescribing in the elderly. Journal of clinical pharmacy and therapeutics. 2007;32(2):11321.

\section{Acknowledgements}

This article was part of a Master's thesis supported by Kerman University of Medical Sciences.

\section{Funding}

This research was financially supported by Kerman University of Medical Science and the Health Services Management Research Center, Institute for Future Studies, Kerman University of Medical Sciences, through Grant No.: 930449.

\section{Author information}

Affiliations

Research Center for Health Services Administration, Institute of Future Studies in Health, Kerman University of Medical Sciences, Kerman, Iran.

Vida Kardanmoghadam, Leila Vali \& Mohammadreza Amiresmaili

Neurology Research Center, Kerman University of Medical Sciences, Kerman, Iran.

Narges Khanjani

Health Technology Assessment Group, Deputy of Treatment, Ministry of Health and Medical Education, Tehran, Iran

Kourosh Rajabkhah

Contributions

All authors made substantial contributions to the conception or design of the work. VK, LV and MR-A acquired the data. VK and $\mathrm{N}-\mathrm{KH}$ analysed the data. VK, LV, MR-A and N-KH had access to and interpreted the data. VK and $\mathrm{KR}$ drafted the manuscript and all authors critically revised it for intellectual content. All authors have read and approved the final manuscript and agree to be accountable for all aspects of the work.

Corresponding author

Correspondence to Mohammadreza Amiresmaili. 


\section{Ethics declarations}

Ethics approval and consent to participate

Ethical approval was obtained from the Ethics Committee of Kerman University of Medical Science (Ethics No. IR.KMU.REC.1393.549). All methods were carried out in accordance with relevant guidelines and regulations. A written informed consent to participate the interview was presented by investigators at the beginning of face-to-face interviews. Participants were informed about the purpose and methods of the study. Their participation was voluntary, and they had the right to withdraw from the study at any time. Written informed consent would be obtained from all participants. Some residents were illiteracy, we obtained proxy consent from a family member or another supportive adult on their behalf.

Consent for publication

Not applicable

Competing interests

The authors declare that they have no competing interests.

\section{Additional information}

Publisher's Note

Springer Nature remains neutral with regard to jurisdictional claims in published maps and institutional affiliations.

\section{Supplementary Information}

Additional file 1: Table S1. Age beers criteria for potentially inappropriate medication use in older adults used in the study.

Additional file 2: Table S2. Nottingham Health Profile: Standard questionnaire used in the study.

Additional file 3: Table S3. Demographic Questionnaire

Additional file 4: Author information 
Table 2: Comparison of the relative frequency of components of QoL in the elderly according to gender, age ,marital status, Education, and Job

\begin{tabular}{|c|c|c|c|c|c|c|c|c|c|c|c|c|c|c|c|c|}
\hline & & \multirow[b]{2}{*}{ Variable } & \multicolumn{2}{|c|}{ Sex } & \multicolumn{3}{|c|}{ Age } & \multicolumn{2}{|c|}{ Marital status } & \multicolumn{3}{|c|}{ Education } & \multicolumn{4}{|c|}{ Job } \\
\hline & & & 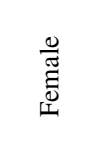 & $\frac{0}{\sum^{\pi}}$ & 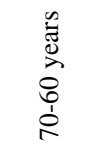 & 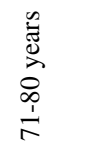 & 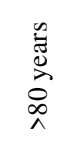 & : & $\begin{array}{l}\overrightarrow{0} \\
\frac{0}{0} \\
\frac{0}{3} \\
3\end{array}$ & 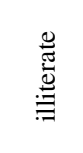 & 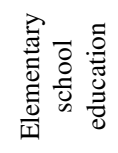 & 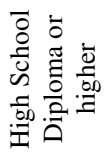 & 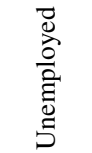 & 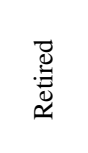 & 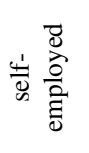 & $\begin{array}{l}\stackrel{9}{3} \\
0 \\
0 \\
0 \\
.\end{array}$ \\
\hline \multirow{11}{*}{ 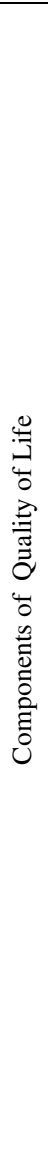 } & \multirow{2}{*}{ 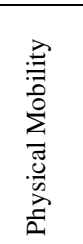 } & $\begin{array}{c}\text { Desirable frequency } \\
\text { (Percent) } \\
(0-45.21) \\
\end{array}$ & $\begin{array}{c}32 \\
(41.6)\end{array}$ & $43(58.9)$ & $\begin{array}{c}47 \\
(67.5)\end{array}$ & $\begin{array}{c}24 \\
(41.4)\end{array}$ & $\begin{array}{c}6 \\
(24)\end{array}$ & $\begin{array}{c}57 \\
(64)\end{array}$ & $\begin{array}{c}18 \\
(31)\end{array}$ & $\begin{array}{c}47 \\
(47.5)\end{array}$ & $\begin{array}{c}23 \\
(59)\end{array}$ & $\begin{array}{c}5 \\
(41.7)\end{array}$ & $\begin{array}{c}20 \\
(40.8)\end{array}$ & $\begin{array}{c}22 \\
(57.9)\end{array}$ & $\begin{array}{c}21 \\
(61.8)\end{array}$ & $\begin{array}{c}12 \\
(41.4)\end{array}$ \\
\hline & & $\begin{array}{c}\text { Undesirable frequency } \\
\text { (Percent) } \\
((45.22-100)\end{array}$ & $\begin{array}{c}45 \\
(58.4)\end{array}$ & $\begin{array}{c}30 \\
(41.1)\end{array}$ & $\begin{array}{c}22 \\
(32.8)\end{array}$ & $\begin{array}{c}34 \\
(58.6)\end{array}$ & $\begin{array}{c}19 \\
(76)\end{array}$ & $\begin{array}{c}32 \\
(36)\end{array}$ & $\begin{array}{c}40 \\
(69)\end{array}$ & $\begin{array}{c}52 \\
(52.5)\end{array}$ & $\begin{array}{c}16 \\
(41)\end{array}$ & $\begin{array}{c}7 \\
(58.3)\end{array}$ & $\begin{array}{c}29 \\
(59.2)\end{array}$ & $\begin{array}{c}16 \\
(42.1)\end{array}$ & $\begin{array}{c}13 \\
(38.2)\end{array}$ & $\begin{array}{c}17 \\
(58.6)\end{array}$ \\
\hline & \multirow{2}{*}{ 摸 } & $\begin{array}{c}\text { Desirable frequency } \\
\text { (Percent) } \\
(0-45.21) \\
\end{array}$ & $\begin{array}{c}37 \\
(48.1)\end{array}$ & $\begin{array}{c}38 \\
(52.1)\end{array}$ & $\begin{array}{c}41 \\
(61.2)\end{array}$ & $\begin{array}{c}28 \\
(48.3)\end{array}$ & $\begin{array}{c}6 \\
(24)\end{array}$ & $\begin{array}{c}51 \\
(57.3)\end{array}$ & $\begin{array}{c}23 \\
(39.7)\end{array}$ & $\begin{array}{c}50 \\
(50.5)\end{array}$ & $\begin{array}{c}19 \\
(48.7)\end{array}$ & $\begin{array}{c}6 \\
(50)\end{array}$ & $\begin{array}{c}25 \\
(51)\end{array}$ & $\begin{array}{c}21 \\
(55.3)\end{array}$ & $\begin{array}{c}16 \\
(47.1)\end{array}$ & $\begin{array}{c}13 \\
(44.8)\end{array}$ \\
\hline & & $\begin{array}{c}\text { Undesirable frequency } \\
\text { (Percent) } \\
((45.22-100)\end{array}$ & $\begin{array}{c}40 \\
(51.9)\end{array}$ & $\begin{array}{c}35 \\
(47.9)\end{array}$ & $\begin{array}{c}26 \\
(38.8)\end{array}$ & $\begin{array}{c}30 \\
(51.7)\end{array}$ & $\begin{array}{c}19 \\
(76)\end{array}$ & $\begin{array}{c}38 \\
(42.7)\end{array}$ & $\begin{array}{c}35 \\
(60.3)\end{array}$ & $\begin{array}{c}49 \\
(49.5)\end{array}$ & $\begin{array}{c}20 \\
(51.3)\end{array}$ & $\begin{array}{c}6 \\
(50)\end{array}$ & $\begin{array}{c}24 \\
(49)\end{array}$ & $\begin{array}{c}17 \\
(44.7)\end{array}$ & $\begin{array}{c}18 \\
(52.9)\end{array}$ & $\begin{array}{c}16 \\
(55.2)\end{array}$ \\
\hline & \multirow{2}{*}{$\frac{\text { बें }}{\tilde{\Sigma}}$} & $\begin{array}{c}\text { Desirable frequency } \\
\text { (Percent) } \\
(0-45.21)\end{array}$ & $\begin{array}{c}37 \\
(48.1)\end{array}$ & $\begin{array}{c}42 \\
(57.5)\end{array}$ & $\begin{array}{c}41 \\
(61.2)\end{array}$ & $\begin{array}{c}30 \\
(51.7)\end{array}$ & $\begin{array}{c}8 \\
(32)\end{array}$ & $\begin{array}{c}53 \\
(59.6)\end{array}$ & $\begin{array}{c}25 \\
(43.1)\end{array}$ & $\begin{array}{c}49 \\
(49.5)\end{array}$ & $\begin{array}{c}22 \\
(56.4)\end{array}$ & $\begin{array}{c}8 \\
(66.7)\end{array}$ & $\begin{array}{c}19 \\
(38.8)\end{array}$ & $\begin{array}{c}27 \\
(71.1)\end{array}$ & $\begin{array}{c}17 \\
(50)\end{array}$ & $\begin{array}{c}16 \\
(55.2)\end{array}$ \\
\hline & & $\begin{array}{c}\text { Undesirable frequency } \\
\text { (Percent) } \\
((45.22-100)\end{array}$ & $\begin{array}{c}40 \\
(51.9)\end{array}$ & $\begin{array}{c}31 \\
(42.5)\end{array}$ & $\begin{array}{c}26 \\
(38.8)\end{array}$ & $\begin{array}{c}28 \\
(48.3)\end{array}$ & $\begin{array}{c}17 \\
(68)\end{array}$ & $\begin{array}{c}36 \\
(40.4)\end{array}$ & $\begin{array}{c}33 \\
(56.9)\end{array}$ & $\begin{array}{c}50 \\
(50.5)\end{array}$ & $\begin{array}{c}17 \\
(43.6)\end{array}$ & $\begin{array}{c}4 \\
(33.3)\end{array}$ & $\begin{array}{c}30 \\
(61.2)\end{array}$ & $\begin{array}{c}11 \\
(28.9)\end{array}$ & $\begin{array}{c}17 \\
(50)\end{array}$ & $\begin{array}{c}13 \\
(44.8)\end{array}$ \\
\hline & \multirow{2}{*}{ 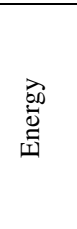 } & $\begin{array}{c}\text { Desirable frequency } \\
\text { (Percent) } \\
(0-45.21)\end{array}$ & $\begin{array}{c}32 \\
(41.6)\end{array}$ & $\begin{array}{c}43 \\
(58.9)\end{array}$ & $\begin{array}{c}38 \\
(56.7)\end{array}$ & $\begin{array}{c}32 \\
(55.2)\end{array}$ & $\begin{array}{c}5 \\
(20)\end{array}$ & $\begin{array}{c}58 \\
(65.2)\end{array}$ & $\begin{array}{c}17 \\
(29.3)\end{array}$ & $\begin{array}{c}44 \\
(44.4)\end{array}$ & $\begin{array}{c}25 \\
(64.1)\end{array}$ & $\begin{array}{c}6 \\
(50)\end{array}$ & $\begin{array}{c}22 \\
(44.9)\end{array}$ & $\begin{array}{c}25 \\
(65.8)\end{array}$ & $\begin{array}{c}18 \\
(52.9)\end{array}$ & $\begin{array}{c}10 \\
(34.5)\end{array}$ \\
\hline & & $\begin{array}{c}\text { Undesirable frequency } \\
\text { (Percent) } \\
((45.22-100) \\
\end{array}$ & $\begin{array}{c}45 \\
(58.4)\end{array}$ & $\begin{array}{c}30 \\
(41.1)\end{array}$ & $\begin{array}{c}29 \\
(43.3)\end{array}$ & $\begin{array}{c}26 \\
(44.8)\end{array}$ & $\begin{array}{c}20 \\
(80)\end{array}$ & $\begin{array}{c}31 \\
(34.8)\end{array}$ & $\begin{array}{c}41 \\
(70.7)\end{array}$ & $\begin{array}{c}55 \\
(55.6) \\
\end{array}$ & $\begin{array}{c}14 \\
(35.9)\end{array}$ & $\begin{array}{c}6 \\
(50)\end{array}$ & $\begin{array}{c}27 \\
(55.1)\end{array}$ & $\begin{array}{c}13 \\
(34.2)\end{array}$ & $\begin{array}{c}16 \\
(47.1)\end{array}$ & $\begin{array}{c}19 \\
(65.5)\end{array}$ \\
\hline & \multirow{2}{*}{ 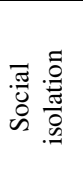 } & $\begin{array}{c}\text { Desirable frequency } \\
\text { (Percent) } \\
(0-45.21)\end{array}$ & $\begin{array}{c}37 \\
(48.1)\end{array}$ & $\begin{array}{c}49 \\
(67.1)\end{array}$ & $\begin{array}{c}47 \\
(70.1)\end{array}$ & $\begin{array}{c}33 \\
(56.9)\end{array}$ & $\begin{array}{c}6 \\
(24)\end{array}$ & $\begin{array}{c}69 \\
(77.5)\end{array}$ & $\begin{array}{c}17 \\
(29.3)\end{array}$ & $\begin{array}{c}51 \\
(51.5)\end{array}$ & $\begin{array}{c}27 \\
(69.2)\end{array}$ & $\begin{array}{c}8 \\
(66.7)\end{array}$ & $\begin{array}{c}26 \\
(53.1)\end{array}$ & $\begin{array}{c}29 \\
(76.3)\end{array}$ & $\begin{array}{c}20 \\
(58.8)\end{array}$ & $\begin{array}{c}11 \\
(37.9)\end{array}$ \\
\hline & & $\begin{array}{c}\text { Undesirable frequency } \\
\text { (Percent) } \\
((45.22-100)\end{array}$ & $\begin{array}{c}40 \\
(51.9)\end{array}$ & $\begin{array}{c}24 \\
(32.9)\end{array}$ & $\begin{array}{c}20 \\
(29.9)\end{array}$ & $\begin{array}{c}25 \\
(43.1)\end{array}$ & $\begin{array}{c}19 \\
(76)\end{array}$ & $\begin{array}{c}22 \\
(22.5)\end{array}$ & $\begin{array}{c}41 \\
(70.7)\end{array}$ & $\begin{array}{c}48 \\
(48.5)\end{array}$ & $\begin{array}{c}12 \\
(30.8)\end{array}$ & $\begin{array}{c}4 \\
(33.3)\end{array}$ & $\begin{array}{c}23 \\
(46.9)\end{array}$ & $\begin{array}{c}9 \\
(23.7)\end{array}$ & $\begin{array}{c}14 \\
(41.2)\end{array}$ & $\begin{array}{c}18 \\
(62.1)\end{array}$ \\
\hline & 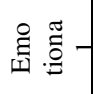 & $\begin{array}{c}\text { Desirable frequency } \\
\text { (Percent) } \\
(0-45.21)\end{array}$ & $\begin{array}{c}35 \\
(45.5)\end{array}$ & $\begin{array}{c}40 \\
(54.8)\end{array}$ & $\begin{array}{c}34 \\
(50.7)\end{array}$ & $\begin{array}{c}31 \\
(53.4)\end{array}$ & $\begin{array}{c}10 \\
(40)\end{array}$ & $\begin{array}{c}49 \\
(55.1)\end{array}$ & $\begin{array}{c}26 \\
(44.8)\end{array}$ & $\begin{array}{c}43 \\
(43.4)\end{array}$ & $\begin{array}{c}23 \\
(59)\end{array}$ & $\begin{array}{c}9 \\
(75)\end{array}$ & $\begin{array}{c}16 \\
(32.7)\end{array}$ & $\begin{array}{c}22 \\
(57.9)\end{array}$ & $\begin{array}{c}19 \\
(55.9)\end{array}$ & $\begin{array}{c}18 \\
(62.1)\end{array}$ \\
\hline
\end{tabular}




\begin{tabular}{|c|c|c|c|c|c|c|c|c|c|c|c|c|c|c|c|}
\hline & $\begin{array}{c}\text { Undesirable frequency } \\
\text { (Percent) } \\
((45.22-100)\end{array}$ & $\begin{array}{c}42 \\
(54.5)\end{array}$ & $\begin{array}{c}33 \\
(45.2)\end{array}$ & $\begin{array}{c}33 \\
(49.3)\end{array}$ & $\begin{array}{c}27 \\
(46.6)\end{array}$ & $\begin{array}{c}15 \\
(60)\end{array}$ & $\begin{array}{c}40 \\
(44.9)\end{array}$ & $\begin{array}{c}32 \\
(55.2)\end{array}$ & $\begin{array}{c}56 \\
(56.6)\end{array}$ & $\begin{array}{c}16 \\
(41)\end{array}$ & $\begin{array}{c}3 \\
(25)\end{array}$ & $\begin{array}{c}33 \\
(67.3)\end{array}$ & $\begin{array}{c}16 \\
(42.1)\end{array}$ & $\begin{array}{c}15 \\
(44.1)\end{array}$ & $\begin{array}{c}11 \\
(37.9)\end{array}$ \\
\hline \multirow{2}{*}{ 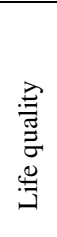 } & $\begin{array}{c}\text { Desirable frequency } \\
\text { (Percent) } \\
(0-45.21)\end{array}$ & $\begin{array}{c}32 \\
(41.6)\end{array}$ & $\begin{array}{c}43 \\
(58.9)\end{array}$ & $\begin{array}{c}42 \\
(62.7)\end{array}$ & $\begin{array}{c}28 \\
(48.3)\end{array}$ & $\begin{array}{c}5 \\
(20)\end{array}$ & $\begin{array}{c}56 \\
(62.9)\end{array}$ & $\begin{array}{c}19 \\
(32.8)\end{array}$ & $\begin{array}{c}44 \\
(44.4)\end{array}$ & $\begin{array}{c}23 \\
(59)\end{array}$ & $\begin{array}{c}8 \\
(66.7)\end{array}$ & $\begin{array}{c}20 \\
(40.8)\end{array}$ & $\begin{array}{c}25 \\
(65.8)\end{array}$ & $\begin{array}{c}18 \\
(52.9)\end{array}$ & $\begin{array}{c}12 \\
(41.4)\end{array}$ \\
\hline & $\begin{array}{l}\text { Undesirable frequency } \\
\text { (Percent) } \\
((45.22-100)\end{array}$ & $\begin{array}{c}45 \\
(58.4)\end{array}$ & $\begin{array}{c}30 \\
(41.1)\end{array}$ & $\begin{array}{c}25 \\
(37.3)\end{array}$ & $\begin{array}{c}30 \\
(51.7)\end{array}$ & $\begin{array}{c}20 \\
(80)\end{array}$ & $\begin{array}{c}33 \\
(37.1)\end{array}$ & $\begin{array}{c}39 \\
(67.2)\end{array}$ & $\begin{array}{c}55 \\
(55.6)\end{array}$ & $\begin{array}{c}16 \\
(41)\end{array}$ & $\begin{array}{c}4 \\
(33.3)\end{array}$ & $\begin{array}{c}29 \\
(59.2)\end{array}$ & $\begin{array}{c}13 \\
(34.2)\end{array}$ & $\begin{array}{c}16 \\
(47.1)\end{array}$ & $\begin{array}{c}17 \\
(58.6)\end{array}$ \\
\hline
\end{tabular}




\section{Supplementary Files}

This is a list of supplementary files associated with this preprint. Click to download.

- Additionalfile1TableS1.pdf

- Additionalfile2Tables2.pdf

- Additionalfile3Tables3.docx

- Additionalfile4Authorinformation.docx

- Additionalinformation.docx 